\title{
Más allá de las paredes del museo: un enfoque de diseño especulativo para el museo del futuro
}

\author{
Beyond museum walls: A speculative design approach to the museum \\ of the future
}

\author{
Jose Hopkins ${ }^{a}$, Danique Hofstee ${ }^{b}$ y Vanessa Cantinho de Jesus ${ }^{c}$ \\ ${ }^{\mathrm{a}}$ Universidad de Utrecht, josohopkins@gmail.com ${ }^{\mathrm{b}}$ Hogeschool Saxion \\ daniquehofstee@hotmail.com ${ }^{c}$ Universidad de Amsterdam vanessacantinhojesus@hotmail.com
}

\begin{abstract}
Resumen
Actualmente algunos museos, particularmente en el norte global, están replanteando su rol social y politico. Muchos de los esfuerzos que apuntaban a la recolección, conservación y exhibición de objetos y prácticas, están siendo redirigidos hacia la construcción de herramientas para la renovación social colaborativa. En varios casos, marcos teóricos como el post-humanismo, el pensamiento relacional, asi como tecnologías digitales, han servido para repensar la definición e implementación de impacto. Muchos teóricos y profesionales coinciden en que tratar de encontrar una relación causal directa entre los museos y un impacto concreto es limitante (ej. Stone, 2001). Nosotros estamos de acuerdo con estos enfoques críticos y creemos en un acercamiento al impacto enfocado en acciones parte un proceso continuo. De esta manera, vemos el futuro de los museos enraizado en una relación bidireccional (o múltiple) entre la institución y la trama social. Creemos que redefinir el acercamiento conceptual a impacto es una herramienta poderosa para romper con la mirada unidireccional y absolutista que muchos museos han tenido y asi posicionarlos como potenciales plataformas contestatarias cuyos movimientos surjan de entre la trama social. Este nuevo enfoque propone entender al museo no como un generador de cambio, pero como un activador de la trama social, incorporándola y haciéndola indispensable, al punto que sea marcar sus diferencias.
\end{abstract}

En este artículo, revisaremos y construiremos sobre algunos de estos acercamientos apoyándonos en el diseño especulativo. Esta metodología ha demostrado ser útil para la solución creativa de problemas y hemos visto que aplicarlo dentro del campo de los museos, especialmente la crisis social y sanitaria actual, es muy fructífera. Esta propuesta parte de un proyecto de 
investigación desarrollado para el Museo de Arnhem en los Países Bajos, en el que desarrollamos diseños especulativos replanteando la forma en que el museo entendía impacto y, de esta forma, se relacionaba con su contexto social inmediato. (https://speculative-musea.webflow.io/)

Por lo tanto, nos acercaremos conceptualmente las paredes o límites del museo como si fuesen un medio. Las ideas de Marshall MacLuhan (1964), quien siguiere que la forma y el medio del mensaje determinan cómo ese mensaje es percibido, guiarán nuestra investigación. Asimismo, el concepto de "muros como medio" buscará contribuir a las discusiones actuales sobre cómo los museos pueden, alternativamente, comprender e implementar el concepto de impacto. Este artículo propondrá un acercamiento conceptual construido a partir de los esfuerzos de entender la participación como una relación entrelazada y rizomática con el tejido social.

Palabras clave: post-humanismo; impacto; diseño especulativo; museos digitales; rizomas; medios digitales

\begin{abstract}
Currently, museums around the world are raising issues regarding their role. Namely, they shift from an approach concerning collecting, conserving, and exhibiting to play a role as an instrument for bottom-up participation and social renewal. Inspired by theoretical frameworks like post-humanism and relational thinking, and digital technologies, one of the issues under scrutiny concerns the definition and measurement of impact. Many theorists and practitioners concur that finding a direct causal relationship between museums and concrete impact is a limiting approach (e.g. Stone, 2001). Similarly, we believe that it can only foster limited and single, goal-oriented actions instead of actions that are part of an ongoing change process. Following a more dynamic position, we see museums' future as bi-directional (or better, multiple) relationships within the social fabric. In this context, impact is redefined through museums becoming dialectic platforms for discussing society from within society. As they lose their absolutist stance, museums become contestants in potentia. This approach leads to a powerful activation of the social fabric, incorporating it - making it indispensable - to the point that differentiating the museum from its potential public becomes nearly impossible.
\end{abstract}

This paper will review and build on some of such alternatives, particularly aided by a speculative design framework. We believe that this approach currently holds extraordinary power because of the social and sanitary crisis. Departing from a practical research design project developed for Museum Arnhem in the Netherlands, we present an example of the potential of such an 
approach for museums' future and a redefinition of impact. (https://speculative-musea.webflow.io/)

We start by proposing to conceptually rethink the museum walls, their limits as a medium. Following the ideas of Marshall McLuhan (1964), who suggested that a message's form determines how that message is perceived and shaped, we speculate on novel forms to reimagine such walls. Playing with the concept of "walls as a medium", we seek to contribute to the current discussions regarding how museums can alternatively understand and perform impact. From this perspective, we can reach an enhanced framework that expands the contemporary participative trend into a network-like relationship where the walls act their medium like nature as speculative action nodes in the social fabric.

Keywords: post-humanism; impact; speculative design; digital museums; rhizomes; digital media 


\section{Introducción}

Este artículo presenta parte de los resultados de las discusiones, investigaciones y ejercicios de tres investigadores que se conocieron en el contexto de una residencia de arte de diseño en Fillip Studios en los Países Bajos (proyecto completo https://speculativemusea.webflow.io). El principal interesado y caso de estudio fue el Museo Arnhem, una institución de arte moderno y contemporáneo que estaba interesada en explorar alternativas para entender el concepto de impacto y distintas formas de abordarlo dentro del contexto de la pandemia del COVID-19. El museo vio esta "nueva normalidad" como una oportunidad para investigar su manera de abordar y entender su relación con sus visitantes.

En este marco, decidimos proponer una serie de soluciones especulativas a partir de la relectura de una serie de discusiones alrededor de la forma que los museos se relacionaban con su público o su contexto inmediato. En lugar de buscar nuevas herramientas para medir el impacto, detectamos que la manera en que se teoriza este concepto es un problema más profundo que el Museo Arnhem no estaba tomando en consideración. Argumentamos que un tema clave subyacente en las discusiones que revisamos y que el museo perpetúa, es que los museos se entienden a sí mismos como completamente (e incluso ontológicamente) separados de su público. En otras palabras, ambas partes son entidades separadas. Creemos que esto perpetúa una posición en la que los museos están continuamente tentados a producir y medir un tipo de impacto unidireccional y de largo plazo basado en una dinámica de causa y efecto. En este artículo deseamos cuestionar esta dicotomía y proponer entender el museo y su tejido social como una relación continua que, a manera de rizoma, se entrelazan entre ellas. Es decir que los museos y su tejido social están entrelazados. Bajo esta premisa, proponemos un acercamiento al impacto de los museos del futuro que no parte de una distancia con la sociedad, sino que emerja desde su interior.

Para alcanzar la idea de continuidad entre el museo y su contexto, realizamos el ejercicio heurístico de repensar las paredes del museo, símbolo de esta separación, como un medio. Con la ayuda del trabajo teórico de Marshall McLuhan, exploramos las posibilidades de repensar las paredes de los museos como medios. Potencialmente, los muros son tanto fronteras como plataformas espaciales que guían la relación entre la entidad a la que enmarcan y su contexto inmediato. Los muros como medios son plataformas abiertas y dialécticas que se hacen con sociedad desde la sociedad. Para concretar esta idea, utilizamos un enfoque de diseño especulativo y presentamos tres propuestas de posibles futuros de los museos. Estas propuestas están destinadas a servir como herramientas de pensamiento que permitan imaginar a distintos profesionales y teóricos de los museos nuevas formas de posicionarse desde dentro del tejido social.

Este artículo está estructurado en tres secciones. La primera presenta una breve discusión de algunos debates actuales en torno a la redefinición del concepto de impacto dentro de los museos. En la segunda, partimos de la dicotomía identificada en estos debates para repensar las paredes del museo como un medio. Este ejercicio heurístico estará guiado por el trabajo 
de McLuhan. Finalmente, en la tercera, presentamos el enfoque de diseño especulativo y tres propuestas de diseño que desarrollamos desde esta perspectiva teórica.

\section{SECCIÓN 1}

\section{Reinventando el museo}

En las últimas décadas, un conjunto de trabajo teórico y práctico que discuten de manera crítica la identidad y el rol social de los museos y otras instituciones culturales ha ido surgiendo en el norte de Europa, el Reino Unido y Australia. Por ejemplo, Carol Scott (2003), John Holden (2004) y Linda Kelly (2007) han discutido algunos temas relacionados a la relación entre los museos y sus públicos, los sistemas de financiación y los actores que los apoyan. Gran parte de esta conversación se desencadena por el cambio de entender a los museos como espacios para legitimar, archivar y exhibir artefactos valiosos hacia entenderlos como instrumentos funcionales para la renovación urbana, la integración y el cambio social (Jowell, 2004).

El problema no es nuevo y en varios momentos ha causado polémica. Por ejemplo, en una de las reuniones más recientes del Consejo Internacional de Museos en la que se abordó principalmente la redefinición del museo (Marshall, 2020). Después de un largo proceso de consulta con miembros de todo el mundo, las propuestas que tenían un enfoque funcionalista (las que entendían al museo como instrumentos) encontraron resistencia por parte de algunos de los socios, al punto que llevó a varias renuncias del comité. Sin embargo, existen varios ejemplos de instituciones o proyectos que aplican estos valores y persiguen dichos objetivos. Por ejemplo, se promovieron las actividades impulsadas por la comunidad del Museo de Oakland (Jones, 2019) o las iniciativas del Statens Museum que promueven la participación cívica de los jóvenes (Sanderhoff, 2019). Aparentemente, estos socios consideraron que definir los museos en torno a su potencial funcionalista como fomentar diálogos democráticos y contribuir a la dignidad humana, la justicia social y el bienestar planetario era una declaración ideológica. No obstante, pensamos que dentro de estas declaraciones del comité yace un problema más interesante en la crítica del funcionalismo de las instituciones. Para ello, uno de los argumentos de John Holden guiará nuestras ideas. Holden sostiene que entender la cultura y las instituciones culturales como herramientas funcionales para políticas macro crea un estado de dependencia y subordinación que constriñe a los museos (Holden, 2004, p. 26).

\section{3. ¿Y qué sobre el impacto?}

El enfoque funcionalista también se expresa en un cambio equivalente en las ideas en torno a la medición y las expectativas del impacto. El creciente interés en generar bienestar comunitario está influyendo en cómo los museos entienden, miden y aplican el concepto de impacto. Más específicamente, para medirlo, demostrarlo e implementarlo, los museos están 
aplicando índices cuantitativos. En esta línea, Holden sostiene que, en el Reino Unido, el problema no es que los museos comprendan cuantitativamente su impacto. El problema es que este impacto funcionalista se está convirtiendo en el activo más importante del museo a la hora de buscar oportunidades de financiación (Holden, 2004, p. 19). Holden sostiene que privilegiar este enfoque obliga a las instituciones a mostrar cómo los museos contribuyeron a agendas políticas más amplias en lugar de hablar sobre lo que están haciendo por ellos mismos. En este sentido, la necesidad de los museos de actuar como agentes sociales en su comunidad (y mejorar la calidad de vida de las personas) se instrumentaliza a través de esquemas de financiación. En esta misma línea, autores como Linda Kelly y Carol Scott demuestran, para el contexto australiano, cómo la calidad del impacto del museo se define en términos de su valor económico (Kelly, 2007) (Scott, 2003). Esto significa que los museos deben demostrar su relevancia a través de datos cuantificables y numéricos para obtener financiación pública. Particularmente para Scott, esto es un problema porque los gobiernos privilegian este enfoque, lo que limita a los museos y pone en peligro su autonomía (Scott, 2003, p. 47). La financiación se convierte en el lazo que amarra a los museos para lograr la política del gobierno.

Además, observamos que los análisis de Holden, Kelly y Scott revelan un aspecto fundamental del enfoque y la medición del impacto de los museos que influye en su relación con su tejido social. Un elemento esencial de la medida cuantitativa del enfoque funcionalista del impacto de los museos es que los museos se ven a sí mismos como diferentes o separados de su tejido social. Observamos esto en el patrón lineal del enfoque cuantitativo. Como proceso de toma de decisiones basado en evidencias e impulsado por objetivos, este método comprende los efectos del museo en una relación causa-efecto. Se entiende por impacto las acciones de un objeto al entrar en contacto y alterar a otro. Esta situación posiciona al museo como una entidad independiente y separada de su objetivo. En otras palabras, este enfoque cuantitativo requiere que el museo se vea a sí mismo como diferente de su tejido social. Independientemente de la actividad que los museos estén implementando, si seguimos la crítica de Holden, el enfoque cuantitativo siempre exigirá que los museos se diferencien de su público. Si los museos solo aplican las lógicas en torno a datos cuantificables, abordarán su tejido social desde un punto de vista lejano.

Por otro lado, Wendy Stone ha argumentado que es difícil, si no imposible, demostrar que existe una relación causal entre los museos y el impacto tangible que generan. En este sentido, Tessa Jowell sugiere que los legisladores y los museos deben prestar atención a lo que hace la cultura por sí misma. Esto puede resonar con el viejo argumento de "el arte por el arte" o con lo que Holden llama el valor intrínseco de la cultura (Jowell, 2004). Para Holden, es urgente buscar y aplicar el valor intrínseco de la cultura en cómo los museos entienden su impacto y su valor (Holden, 2004, p. 22). Aunque este argumento puede traer de vuelta un enfoque clasista y snob de los museos y la cultura en general, Holden ve este valor como un contrapeso para el abrumador enfoque cuantitativo.

Holden sostiene que el valor intrínseco del arte puede permitir que los museos incluyan resultados cuantitativos y cualitativos. Estos valores son parte de una combinación compleja 
de factores que se derivan de cosas que podría haber o no sucedido. Por ejemplo, las emociones producidas durante una conversación después de una película o la situación en la que escuchar una canción impide que alguien se quite la vida (Holden, 2004, p. 18). El argumento de Holden sugiere la implementación de un enfoque equilibrado de lo que significa e implica impacto. Es una definición que incluye los elementos afectivos de la experiencia, la práctica y la identidad cultural, y la gama completa de datos cuantificables. Este enfoque híbrido puede ayudar a crear instituciones culturales sólidas que confíen en su valor e integrarlas en el tejido social en lugar de existir como una herramienta distante.

Asimismo, la perspectiva de Holden nos permite repensar la distinción entre museos y su público. Su argumento nos proporciona la perspectiva para argumentar y aplicar una relación no basada en lo vectorial de entrada y salida, sino en un rizoma que se cruza y entrelaza con diferentes aspectos de los visitantes. En otras palabras, ambas entidades están integrando partes del mismo tejido social. De manera similar al impacto en la canción que evita una tragedia, vemos el impacto cualitativo como una herramienta poderosa para romper o cuestionar la diferencia perpetuada por el enfoque cuantitativo.

Pero si damos un paso adicional, quisiéramos sugerir que al cuestionar todas estas discusiones también estas cuestionando la forma en que el museo impacta su tejido social. Entonces, la pregunta cambia de entender el impacto unidireccional, a entenderlo como los modos y la calidad de conexión con los procesos de transformación entre los museos y su tejido social. La figura 1 nos ayuda a ilustrar este punto.

Para profundizar más en esta cuestión e ir más allá de la distinción identificada, recurrimos a un ejercicio heurístico alrededor de las paredes del museo. También servirá como una plataforma para proponer el diseño especulativo como un enfoque útil para imaginar el futuro de dicho compromiso y lidiar con las complejidades del momento histórico actual. 

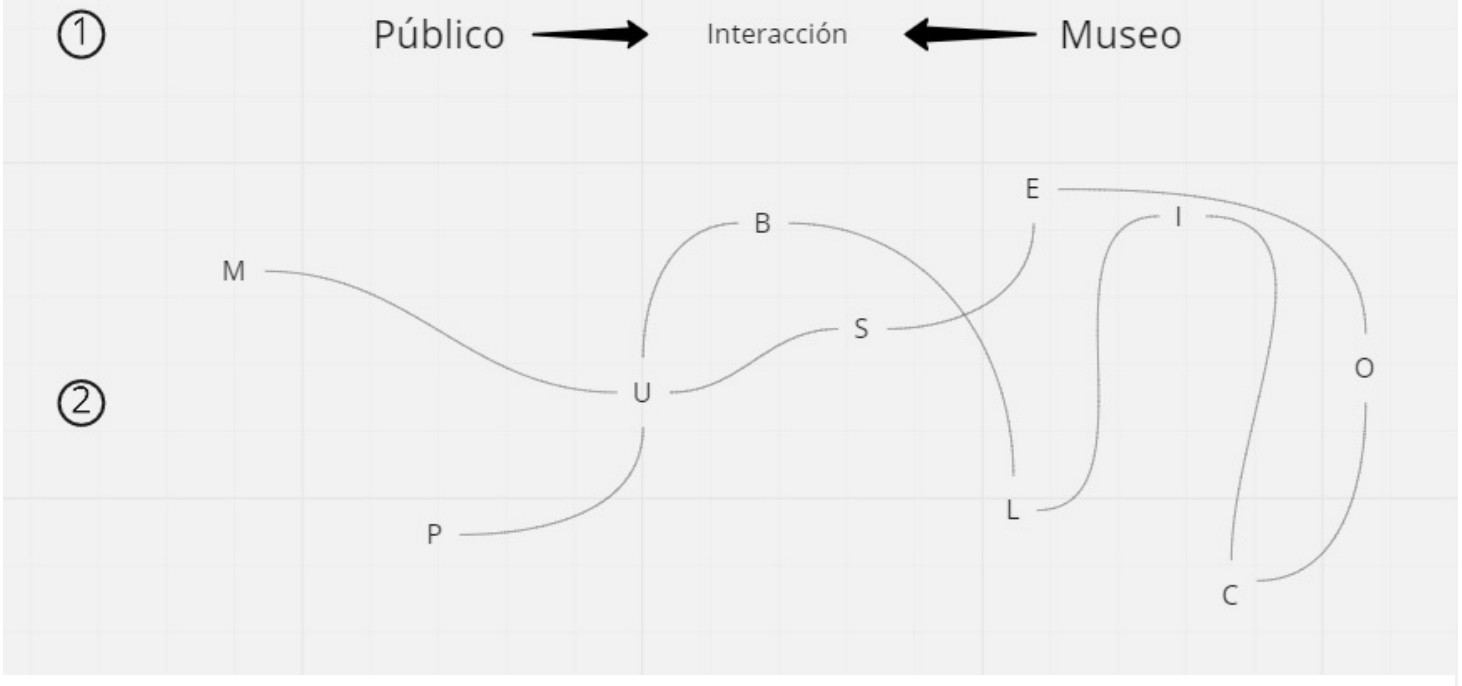

1. Entidades separadas que se encuentran mediante la interacción

2. El museo y el público son parte de la misma entidad y están conectados en y con el tejido social

Fig. 1

\section{SECCIÓN 2}

\section{El medio es la pared}

Nuestro siguiente paso es repensar conceptualmente las paredes del museo como el límite simbólico que lo une al tejido social. Queremos entender estas paredes como si fueren una especie de conector entre dos espacios o agentes. Esto sugiere que, en vez de solo entenderlos como límites de separación, las paredes serían puntos de contacto y fricción que se materializan como coordenadas en el espacio social. Estas coordenadas efectivamente dan forma a los límites y concretan el espacio; pero al hacerlo, funcionan como un medio que permite la materialización del espacio.

Para profundizar en esta idea, utilizaremos el concepto de medio de Marshall McLuhan. ${ }^{1}$ McLuhan explica que los medios son "extensiones de nosotros mismos." Es decir, cualquier cosa que amplíe nuestra existencia y nuestra participación y acción dentro de nuestro entorno.

\footnotetext{
1 "En una cultura como la nuestra, acostumbrada desde hace mucho tiempo a dividir todas las cosas como un medio de control, a veces es un poco chocante recordar que, en el hecho operacional y práctico, el medio es el mensaje. Esto es simplemente para decir que las consecuencias personales y sociales de cualquier medio, o de cualquier extensión de nosotros mismos, resultan la nueva escala que se introduce en nuestros asuntos por cada extensión de nosotros mismos o por cualquier nueva tecnología ". McLuhan, Marshall. Understanding Media: The Extensions of Man. Canada: McGraw-Hill, 1964 - Traduccion por los autores
} 
Son algo como unos facilitadores, herramientas o artefactos que se y nos expanden más allá de nosotros creando canales de comunicación que nos entrelazan con algo más extenso. De esta manera, los medios son cualquier cosa que proveen de sentido al mundo ya que estos dan forma a los contornos y cualidades de esas extensiones. Esto es fundamentalmente a lo que McLuhan se refiere cuando afirma que "el medio es el mensaje." Por otro lado, las cosas que nos expanden hacia el mundo y le dan forma, también nos moldean simultáneamente. Por ejemplo, el estar callados en una biblioteca, ya que no es un estadio de futbol, es producto de cómo un medio, o una serie de medios, nos inducen a comportarnos de una manera específica. De igual manera, nosotros queremos pensar que las paredes de los museos tienen su propia forma de transmitir y dar forma a tu contexto. Entonces, ¿qué pasa si repensamos las paredes de una manera que nos permita volver a aprender y comprender sus límites y prácticas de mapeo? Supongamos que el medio es el mensaje y las paredes son los medios. ¿Qué mensaje pueden transmitir las paredes de los museos como conectores en la red del tejido social?

Al considerar las paredes del museo como un medio, podemos rastrear las implicaciones de los límites y el impacto para repensar el museo y su tejido social como una red bidireccional o multidireccional. Asimismo, podemos describir y analizar críticamente los límites y barreras que los museos están creando y, de esta manera, redefinir la relación (e interacción) entre el museo y su tejido social.

La siguiente sección busca explorar alternativas para repensar la forma en que los visitantes (actuales y potenciales) se mueven desde y a través de los espacios museales. Queremos proponer alternativas que den forma de rizoma al museo, un espacio cuyas paredes no solo demarcan, pero transforman. Para ello, utilizaremos un enfoque capaz de ir más allá de la realidad y así, proponer una serie de prototipos especulativos que son el resultado del ejercicio heurístico de repensar los muros como conectores.

\section{SECCIÓN 3}

\section{Diseño especulativo para tiempos disruptivos}

En las secciones anteriores, discutimos el tema de la conceptualización del impacto en museos. Como expusimos, el enfoque instrumental del museo trajo consigo el privilegio de valores cuantitativos y económicos. El impacto que puede producir este tipo de valores es unidireccional, por lo que posiciona al museo como separado de su tejido social. Sin embargo, encontramos una alternativa para este problema al repensar las paredes del museo como un medio. Esta herramienta conceptual nos permitió diseñar futuros especulativos más allá de la separación del museo de su tejido social. En esta sección, presentaremos nuestro enfoque del diseño especulativo y tres propuestas. Es primordial mencionar que, aunque un diseño se considera una disciplina de resolución de problemas, nuestras sugerencias son alternativas que no se basan en que tan posibles pueden ser, sino en empujar los límites a través de la imaginación.Nuestra visión del diseño especulativo sigue las ideas y métodos de 
Fiona Raby y Anthony Dunne (Dunne \& Raby, 2013), pioneros y líderes en diseño crítico. Ellos explican que el diseño especulativo se nutre de la imaginación y tiene como objetivo abrir nuevas perspectivas. Es una herramienta para crear espacios de debate sobre formas distintas de ser, fomentando la creatividad de las personas a través de proponer escenarios posibles. Por tanto, nuestro proyecto consta de futuros especulativos. Cada diseño parte de la pregunta de "qué pasaría si" para romper las estructuras existentes y construir una experiencia posible. Utilizamos esta metodología para redefinir nuestra relación con los museos y sus muros. El diseño especulativo nos permite enfocarnos en las posibilidades futuras en lugar de crear soluciones para un problema concreto.

Las siguientes propuestas son ideas que pretenden hacer preguntas sobre qué podría abarcar si consideramos las paredes de los museos como un medio. Esto nos permitió acercarnos a los museos no solo como torres de marfil separadas de sus visitantes y dejar de privilegiar el impacto cuantificable y distante. En cambio, nos acercamos a ellos como extensiones de nosotros mismos y así, exploran su potencial de ser plataformas transformadoras. Repensar las paredes del museo no las altera físicamente, sino que nos permite reanalizar y abordar críticamente la manera en que construyen sus límites y el "flujo" de visitantes. En otras palabras, las siguientes preguntas guiaron nuestras propuestas: ¿Dónde comienza y dónde termina el museo? ¿Cómo se mueven e interactúan los visitantes potenciales con él? ¿Cómo pueden las herramientas digitales ayudarnos a elaborar esto conceptual y prácticamente?

\section{Futuro posible \#1: Curando ventanas}

Esta propuesta aborda el tema de los límites del museo de manera bastante literal. Gracias a la tecnología especulativa de paneles solares unida al vidrio, las ventanas pueden comportarse como pantallas. Esto permite que la fachada del edificio se transforme en obras de arte itinerantes de la colección de obras digitales del museo. Además, las imágenes cambiarán a través de la contribución consciente o inconsciente de quienes residen, permanente o temporalmente el edificio. Las obras de arte se seleccionan y varían según las conversaciones, acciones y emociones de los residentes. Las nuevas tecnologías inorgánicas, orgánicas y biónicas han generado un tramo más amplio de los límites del museo en cuanto a ubicación y participación. ¿Dónde está este museo y quién forma parte de él?

Esta propuesta desmantela los límites del museo y lo posiciona como una institución multilocal. Esto significa que este museo ya no está contenido por sus paredes físicas y no está curado únicamente por curadores designados. Cualquier ventana puede convertirse en un muro de exposición (o pantalla), y cualquier habitante puede convertirse en curador. La exhibición de imágenes responde a las respuestas encarnadas del espectador/curador; así, podemos afirmar que la exposición refleja sus pulsaciones y afectos vitales. Este museo permite a los espectadores abrirse y construir activamente su tejido social de diferentes formas expandiéndose hacia las paredes y personalizar los espacios que habitan. 


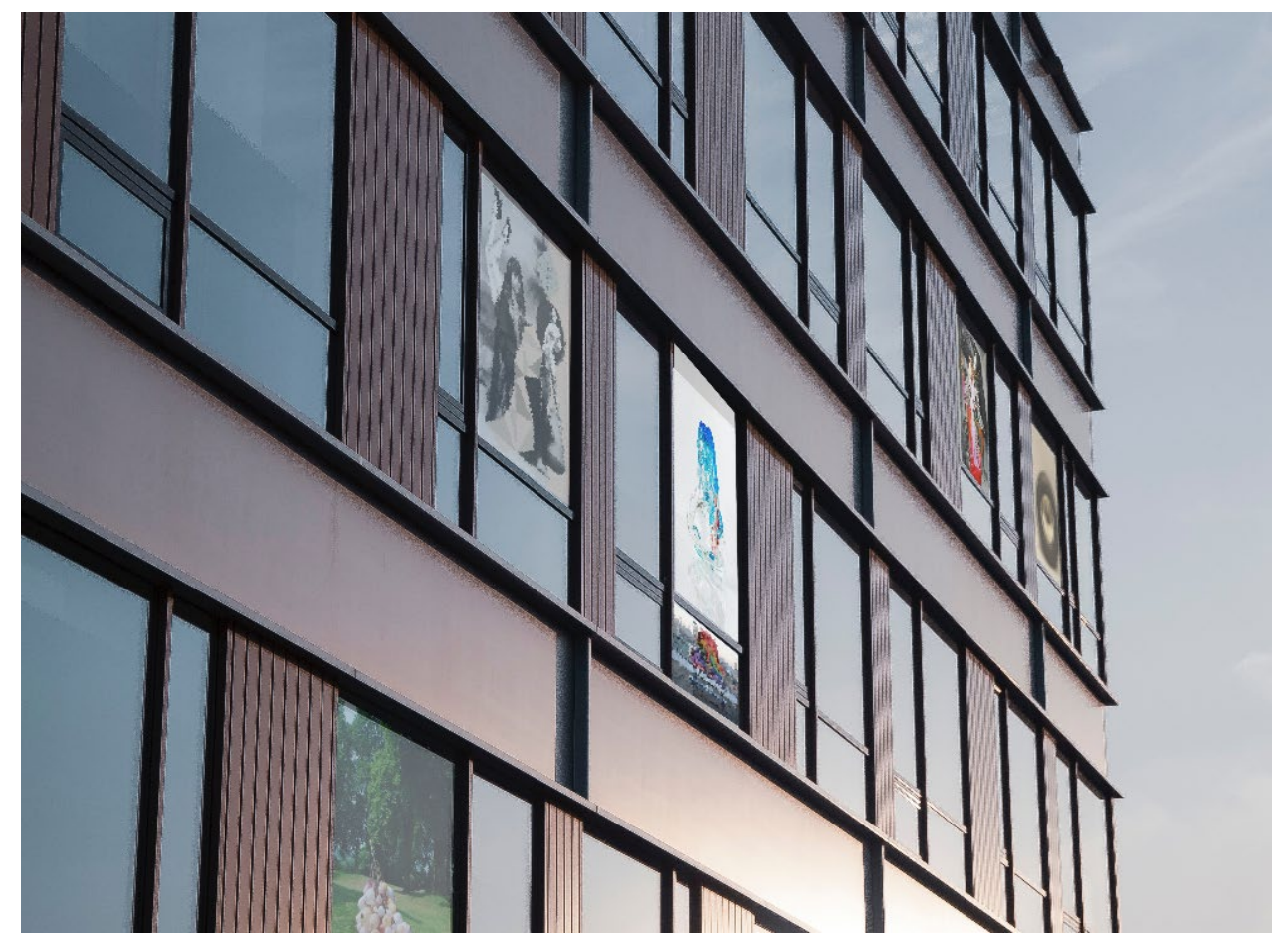

Fig. 2 Curando Ventanas, imagen por Danique Hoofstee

\section{Futuro posible \#2: Una mesa redonda en la ciudad: La pizarra del ágora}

Este diseño especulativo está impulsado por la idea de que las paredes de los museos no cambiaron por completo de forma; aun así, se abren hacia y dentro de la ciudad. El museo se amplía y se convierte en una especie de conjunto de paredes móviles con las que los transeúntes pueden interactuar. Estos muros se pueden utilizar como lugares de reunión efímeros para el debate. Ya no son espacios fijos para visitar y resguardar. En cambio, se centran en el flujo, el movimiento y la interacción en constante cambio del visitante. Permiten un baile libre entre las obras de arte y los visitantes. Lo que domina la esencia de los museos ya no es un espacio que resguarda, sino la forma en que hacen que los visitantes fluyan e interactúen en la serie de eventos que crean. Son museos que no son lugares sino eventos.

Por lo tanto, cada ciudadano se convierte en un visitante potencial y la ciudad entera es un museo posible. Los museos ya no se molestan en llevar a los ciudadanos dentro de sus muros, clasificándolos por visitantes o no visitantes. Los museos se abren y se entrelazan en el tejido social impactando en él en diferentes niveles cuantitativos y cualitativos. Son tan flexibles como las necesidades y peticiones de los "visitantes" de la institución. Este museo no se 
enfoca en contener y compartir, sino que se mueve por el movimiento. Se guían por una interacción similar a la danza que los ciudadanos realizan.

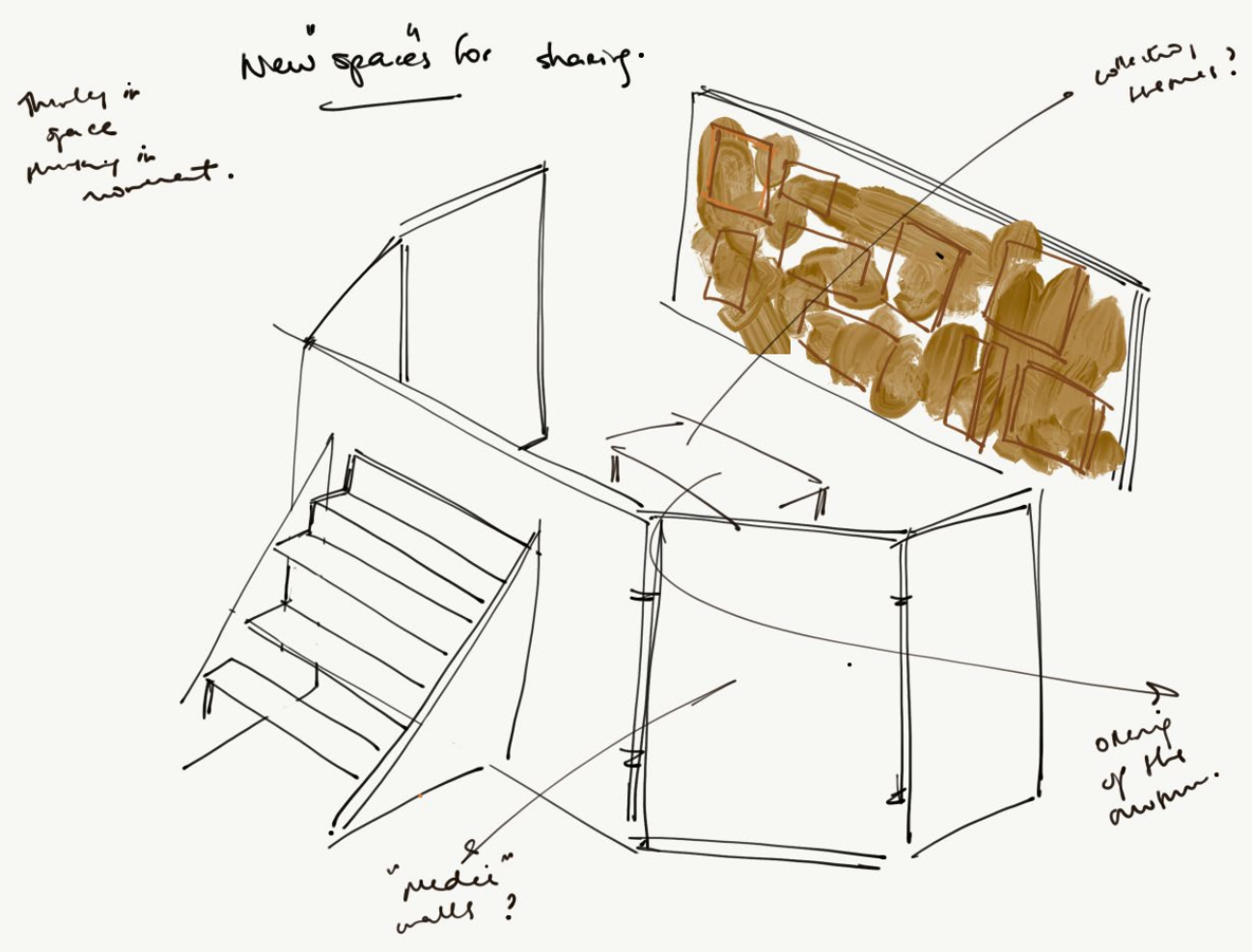

Fig. 3 Una mesa redonda en la ciudad, imagen por Jose Hopkins

\section{Posible futuro \#3: La píldora del museo}

Esta especulación surge de cuestionar los límites del cuerpo. La píldora del museo se propone como una experiencia sana de la encarnación humana donde el usuario se sumerge en una pieza de la colección del museo. La píldora trasciende los límites físicos entre la obra de arte y el espectador ya que, al ingerirla, activa los sentidos y transporta al individuo a una experiencia de sonidos, aromas y colores que parten de y remite a dicha obra de arte. Es decir que temporalmente, la percepción se transforma hasta el punto en que el usuario se deleita con una existencia alterada, rompiendo los límites y expandiendo la intersección entre el cuerpo y el arte. Esta experiencia es un viaje de arte gratuito, donde el museo se proyecta en el hiperespacio. 
Esta propuesta permite que el propio cuerpo se convierta en el espacio de exhibición. También muestra que los objetos del arte son parte de cómo vemos el mundo y cómo nos vemos a nosotros mismos en el mundo. El arte ya no está contenido dentro de las paredes del museo, sino que es parte del participante/visitante/usuario. Se vuelve imposible distinguir la obra de arte del visitante y de su tejido social. En este diseño, queda claro cómo las paredes de los museos se han convertido en una extensión de nosotros mismos, cómo nos transforman y afectan nuestro comportamiento. De igual manera que un estadio nos hace tener fuertes emociones y vínculos con los equipos que juegan, la píldora del museo nos persuade de cambiar temporalmente la experiencia de nuestra relación con el mundo y con el arte.

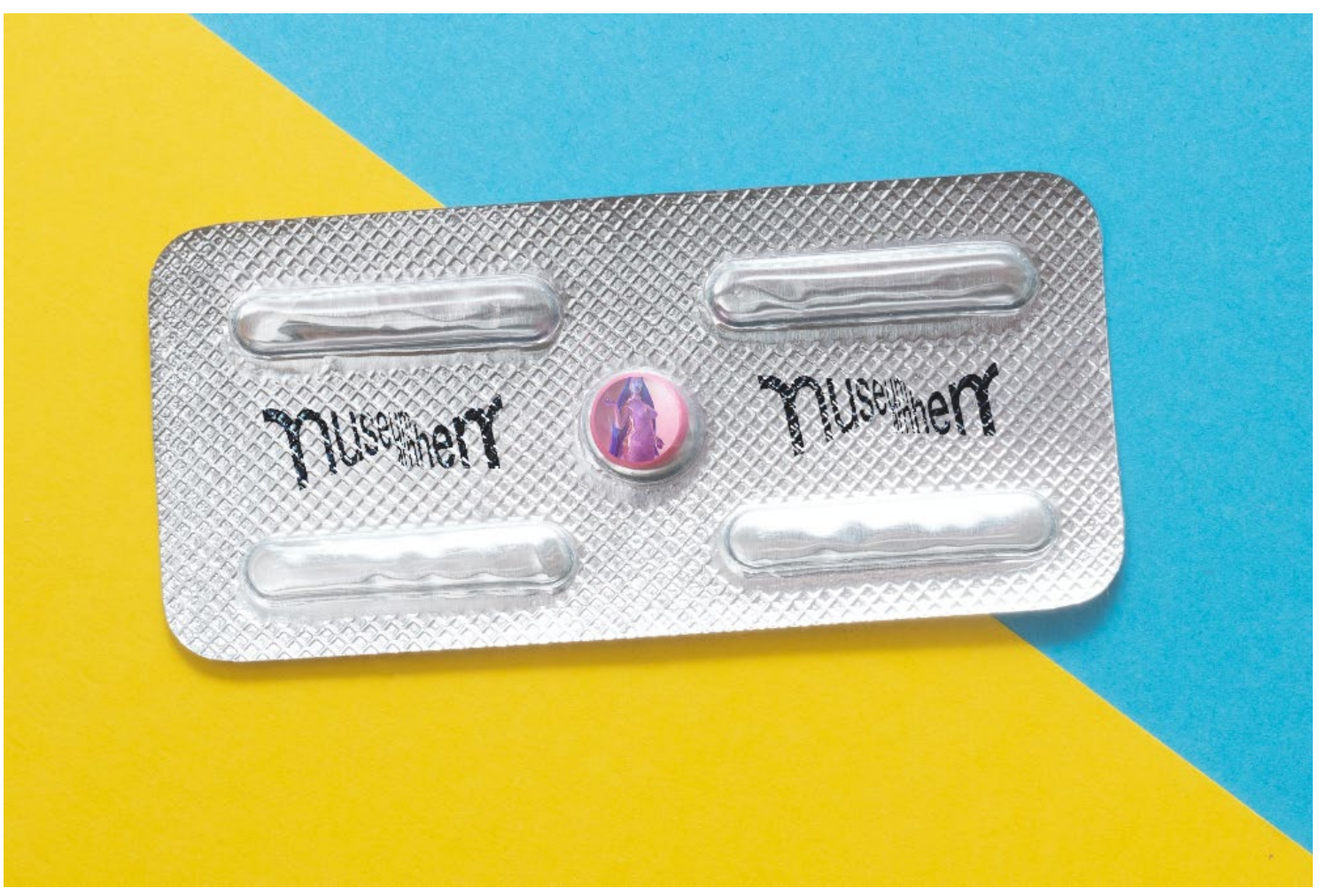

Fig. 4 La píldora del museo, imagen por Danique Hoofstee

\section{Conclusiónes}

Como hemos mostrado en este texto, existe un problema esencial con el uso exclusivo de valores cuantitativos para comprender el impacto del museo. Entre ellas, nos hemos enfocado en indicar que este método privilegia una percepción del impacto unidireccional y de causaefecto. Demostramos que este enfoque afecta la forma en que los museos se posicionan dentro de su tejido social, colocándolos como separados e incluso ontológicamente diferentes. Esta perspectiva, enmarcada dentro de un enfoque funcionalista, privilegia un tipo 
de impacto y una comprensión del cambio social y el bienestar basado en datos medibles. Además, pasa por alto los efectos potenciales inconmensurables que tienen los museos, que son tan importantes como lo que podemos medir.

Como respuesta activa a este problema, nuestro proyecto consistió en vislumbrar y proponer futuros especulativos. Partiendo de la premisa de que es imperativo ver a los museos entrelazados con su tejido social, sugerimos una serie de escenarios que reformulan las estructuras institucionales existentes. Cuando imaginamos que los museos ya están enredados en el mundo, la pregunta se vuelve menos sobre cómo los museos producen impacto y más sobre la calidad de su participación.

Empleamos un enfoque de diseño especulativo guiado por la sugerencia de empezar a entender las paredes de los museos como medios. Este ejercicio dio como resultado una serie de diseños que abordan futuros posibles que desmantelaron los límites de los museos y los fusionaron con las transformaciones, cada vez mayores, de la sociedad. Nos permitió abordar la infraestructura de la que es parte y da forma a los museos como una red, teniendo en cuenta el uso y las relaciones entre las tecnologías, los problemas sociales y el arte. En lugar de simplemente considerar su naturaleza artefactual, un edificio con obras dentro de sus paredes, aplicamos este enfoque para mirar más allá de los parámetros establecidos del impacto.

Creemos que este enfoque y estos diseños especulativos resultaron fructíferos para reconsiderar la posición y las relaciones de la institución dentro de la sociedad. Aunque sabemos que estas propuestas son quizás demasiado radicales y, es posible que carezcan de un enfoque situado y no sean aplicables en el corto plazo; creemos que hemos demostrado su utilidad para iniciar nuevas sinergias. Esperamos que este artículo motive una mayor investigación sobre los enfoques especulativos en los estudios de museos, particularmente en cómo los museos entienden su relación con su contexto inmediato (y no tan inmediato).

Por ejemplo, a medida que se realicen más investigaciones, creemos que es posible explorar y problematizar quién es y dónde se encuentra este "tejido social". Cuantos más museos se vuelcan hacia lo digital y apliquen esas lógicas a su trabajo institucional; creemos que la idea de "contexto inmediato" cambiará. En otras palabras, el tejido social en donde se enreda el museo se transformará. Creemos que nuestro enfoque tiene un gran potencial para esclarecer este problema. 


\section{Referencias}

DUNNE, A., \& RABY, F. (2013). Speculative everything: design, fiction, and social dreaming. Cambridge, Massachussets, London: MIT press.

HOLDEN, J. (2004). Capturing Cultural Value. How culture has become a tool of government policy. London: Demos.

https://speculative-musea.webflow.io/ . (n.d.).

JONES, J. (2019). What problem in our community is our museum most uniquely equipped to solve? Retrieved from Medium: https://medium.com/new-faces-new-spaces/whatproblem-in-our-community-is-our-museum-most-uniquely-equipped-to-solvefe4dce9848b7\#: :text=At $\% 20$ the $\% 20$ Museum $\% 2 C \% 20$ we $\% 20$ create,social $\% 20$ cohesio $\mathrm{n} \% 20$ in\%20our\%20community.

JOWELL, T. (2004). Government and the Value of Culture. London: Department for Culture, Media and Sport.

KELLY, L. (2007). Measuring the impact of museums on their communities: The role of the 21 st century. ICOM International Committee for Museum Management 2006 (INTERCOM). Taipei: INTERCOM.

MARSHALL, A. (2020). What is a museum? A dispute erupts over a new definition. New York Times, pp. https://www.nytimes.com/2020/08/06/arts/what-is-a-museum.html.

SANDERHOFF, M. (2019). Statens Museum for Kunst: The social impact of using art to increase civic participation of young people 2018. Retrieved from Europeana: $\mathrm{https}$ :/pro.europeana.eu/post/statens-museum-for-kunst-the-social-impact-of-using-artto-increase-civic-participation-of-young-people-2018

SCOTT, C. (2003). Museums and Impact. Curator - The Museum Journal, 46(3), 293-310.

SCOTT, C. (2006). Museums: Impact and value. Cultural Trends, 15(1). 